\title{
Preparation of High-Performance Adsorbent From Low- Cost Agricultural Waste (Peanut Husk) Using Full Factorial Design: Application to Dye Removal
}

\author{
Asmadi Ali 1,* ${ }^{\mathbb{D}}$, Alex Wong Chung Ing ${ }^{1}$, Wan Rafizah Wan Abdullah ${ }^{1}$, Sofiah Hamzah ${ }^{1}$, Fazureen \\ Azaman ${ }^{1}$ \\ 1 Faculty of Ocean Engineering Technology and Informatics, Universiti Malaysia Terengganu 21030, Kuala Nerus, \\ Terengganu, Malaysia; thunderking93@hotmail.com; $\quad$ wanrafizah@umt.edu.my; sofiah@umt.edu.my; \\ fazureenazaman92@yahoo.com; \\ * Correspondence: asmadi@umt.edu.my;
}

Scopus Author ID 54790692100

Received: 27.04.2020; Revised: 20.05.2020; Accepted: 22.05.2020; Published: 27.05.2020

\begin{abstract}
Dye pollution becomes one of the significant environmental concerns nowadays. The adsorption technique is a potent method for the removal of the dye from wastewater effluents. Conventional activated carbon is one of the best adsorbents for dye removal. However, it is constraint due to high cost, and problems with regeneration hamper large scale applications. The alternative method using low-cost adsorbent is being introduced to replace the activated carbon since they are available in large quantities, renewable and inexpensive. Hence, peanut husk (Canavalia Ensiformis) as absorbent was investigated for its potential in Malachite Green (MG) dye removal. The effects of dye concentration $(25$ and $100 \mathrm{mg} / \mathrm{L})$, temperature $\left(30\right.$ and $\left.60{ }^{\circ} \mathrm{C}\right)$, and adsorbent dosage $(25$ and 100 $\mathrm{mg}$ ) on MG dye removal percentage were designed and optimized using two levels full factorial design. Based on the optimization process, it was determined that the $25 \mathrm{mg} / \mathrm{L}$ of dye concentration, $60{ }^{\circ} \mathrm{C}$ of temperature, and 100mg of adsorbent dosage resulted in the highest removal efficiency of $84.85 \%$ and $91.83 \%$ for untreated and treated adsorbent, respectively. In conclusion, treated peanut husk has shown its great potential as low-cost adsorbent based on the removal efficiency.
\end{abstract}

Keywords: dye pollution; adsorbent; full factorial design; optimization.

(c) 2020 by the authors. This article is an open-access article distributed under the terms and conditions of the Creative Commons Attribution (CC BY) license (https://creativecommons.org/licenses/by/4.0/).

\section{Introduction}

Water from the textile industries is an ecological problem that causes serious problems for living beings. Approximately one-fifth of industrial water pollution is due to textile processing and dyeing. The textile industry is known to be the largest polluter of clean water with the use of over a thousand chemicals in different coloring and printing processes $[1,2]$. With that, several techniques have been investigated to remove the dye molecules from the effluents such as ion exchange, adsorption, biodegradation, membrane filtration, and others. Adsorption has received considerable attention among the techniques in terms of cost, ease of use, flexibility, and simplicity of design [3,4]. Activated carbon (AC) is one such adsorbent that has excellent potential for dye removal since it has a micro-porous nature, larger surface area, micro-porous nature, and high adsorption capacity [5, 6].

However, activated carbon is restricted due to high prices, high operating costs, and problems with regeneration hamper larger-scale applications. Hence, there is a constant need to find a better adsorbent with renewable, low cost and locally available materials for the 
removal of dye [7, 8]. Numerous low-cost adsorbents for removing dyes have been proposed. These include agricultural waste (sawdust, bark, fruit peel), industrial wastes products (fly ash, red mud, metal hydroxide sludge), clay materials (zeolites, diatomite, dolomite), bioadsorbents (biomass, peat) and others (cotton, starch) [3]. Due to environmental considerations, agricultural wastes are considered an essential precursor. This is because they are cheap in terms of cost, renewable resources, safe, available in large quantities, and easily accusable sources. These are also high in carbon and have low ash content [9].

Besides, the adsorption process depends on several parameters such as $\mathrm{pH}$, temperature, initial solute concentration, and adsorbent dosage used [10, 11]. A popular approach to researching and maximizing the effect of adsorption factors is to use the experimental onefactor-at-a-time (OFAT), which considers measuring the response against one factor, keeping contents for other factors. However, it involves multiple experiments and very time consuming, besides being unable to study the effects of interactions between the factors, rendering a conclusion about optimization unreliable [12]. To draw the effective method, the design of experiment (DoE) can be applied to replace the stated conventional method. Thus, the main objective of this study is to determine the optimum adsorption of dye removal using low-cost peanut husk adsorbent based on initial dye concentration, temperature, and adsorbent dosage via full factorial design.

\section{Materials and Methods}

\subsection{Materials.}

Malachite Green (MG) dye with molecular formula $\mathrm{C}_{23} \mathrm{H}_{25} \mathrm{~N}_{2} \mathrm{Cl}$ (molecular weight $=$ $364.92 \mathrm{~g} / \mathrm{mol}, \lambda_{\max }=617 \mathrm{~nm}$ ) was procured from Bendosen Laboratory Chemicals and was used as the adsorbate. $\mathrm{NaOH}$ pellet with a molecular weight of $40 \mathrm{~g} / \mathrm{mol}$ was prepared to modify untreated peanut husk as treated adsorbent under alkali treatment and $\mathrm{pH}$ adjustment. All reagents were used without further purification, and the study utilized double distilled water.

\subsection{Preparation of adsorbents.}

\subsubsection{Preparation of untreated peanut husk.}

Peanut husks were collected from Material Laboratory located in FTKKI, UMT, Kuala Nerus, Terengganu. The raw peanut husks were thoroughly rinsed with distilled water to get rid of soil, dust, and impurities [13]. After that, peanut husk was bottomed with aluminum foil and put into a universal oven for drying purposes at $105^{\circ} \mathrm{C}$ for 24 hours until crisp. Then, the dried peanut husk was ground into fine powder in an analytical mill [14] and sieved to obtain particles of diameter ranging between $250-500 \mu \mathrm{m}$ by using laboratory sieve [15]. Ziplock bags were prepared to store the sieved pea husk powder, labeled clearly, and placed into desiccator for further purpose.

\subsubsection{Preparation of treated peanut husk.}

A similar procedure was followed for the preparation of treated peanut husk. After the peanut husks were dried and grinded, they were soaked into $0.1 \mathrm{M}$ sodium hydroxide $(\mathrm{NaOH})$ solution for 24 hours at room temperature so that they could fully adsorb all the reagents [16]. 
The alkali solution was filtered off and washed with distilled water to remove any possible residue of $\mathrm{NaOH}$ solution [13]. The $\mathrm{pH}$ was adjusted to nearly neutral. The treated peanut husks were dried again in a universal oven for 24 hours [14]. The preparation was ended with storing the dried peanut husk into a zip lock bag with clearly labeled and placed into desiccator for further purpose.

\subsection{Adsorption experiments.}

The experiment was carried out by batch adsorption method to investigate the effect of temperature, adsorbent dosage, and initial dye concentration [17]. Peanut husk was contacted with $100 \mathrm{~mL}$ Malachite Green (MG) solutions in a sealed $250 \mathrm{~mL}$ conical flask agitated vigorously by using a water bath shaker. The shaken speed was kept constant at 150rpm until equilibrium [18]. The sealed flasks were agitated for time intervals $(10,20,30,40,50,100$, 150 , and 200minutes) until equilibrium reached. Influence of temperature ( 30 and $60^{\circ} \mathrm{C}$ ), initial dye concentration $(25$ and $100 \mathrm{mg} / \mathrm{L})$, and adsorbent dosage $(25$ and $100 \mathrm{mg}$ ) was examined during this research. Samples were collected from the flasks for analysis of the residual dye concentration in each flask at predetermined time intervals. The suspensions were filtered through the Whatman filter paper, and the supernatant was analyzed by measuring absorbance at maximum wavelength $=617 \mathrm{~nm}$ using UV-Vis Spectrophotometer. The removal capacity of MG dye by peanut husk was calculated using Equation (1):

$$
\text { Percentage removal efficiency }(\%)=\frac{C_{o}-C}{C_{o}} \times 100 \%
$$

Where $\mathrm{C}_{\mathrm{o}}$ is an initial concentration of $\mathrm{MG}, \mathrm{mg} / \mathrm{L}$, and $\mathrm{C}$ is $\mathrm{MG}$ concentration after adsorption at a certain time interval, $\mathrm{mg} / \mathrm{L}$. The adsorption experiments were repeated in triplicate to reduce any possible random errors.

\subsection{Characterization of adsorbent.}

Characterization techniques of absorbent involve the morphological study by SEM, FTIR, and Micromeritics ASAP. SEM was used to characterize the surface morphology of the adsorbent materials. The analysis was conducted at 1000x magnification using SEM (JEOLJSM-6610L) in Centralized Lab UMT. FTIR (Shimadzu IR Tracer-100) used to detect the surface functional groups of untreated and treated peanut husk. The specific surface area and pore volume were determined by using nitrogen adsorption-desorption isotherm properties. The analysis was carried out by using Micromeritics ASAP 2000 in Centralized Lab UMT.

\subsection{Design of experiment ( $D o E)$.}

The design of the experiment was carried out using Minitab 16.0 software using a twolevel (23) complete factorial design with 3 replicates. The three selected factors were temperature, initial dye concentration, and adsorbent dosage, while the response was MG dye removal percentage, $\%$. The studied ranges for initial dye concentration, temperature, and adsorbent dosage were between 25 to $100 \mathrm{mg} / \mathrm{L}, 30$ to $60^{\circ} \mathrm{C}$, and 25 to $100 \mathrm{mg}$, respectively. Table 1 summarizes the code levels and their corresponding actual values for three factors. 
Table 1. Coded levels and its actual variables for $2^{k}$ Factorial Design Method

\begin{tabular}{l|c|c|c} 
& \multirow{2}{*}{ Coded Symbol } & \multicolumn{2}{|c}{ Level } \\
\cline { 3 - 4 } Factors & & $-1(\min )$ & $+1(\max )$ \\
\hline Initial dye concentration $(\mathrm{mg} / \mathrm{L})$ & $\mathrm{A}$ & 25 & 100 \\
\hline Temperature & $\mathrm{B}$ & 30 & 60 \\
\hline Adsorbent dosage $(\mathrm{mg})$ & $\mathrm{C}$ & 25 & 100
\end{tabular}

\subsection{Statistical analysis.}

Multiple regression techniques were used to establish the relationship between the response (Removal rate, R) and three factors (initial dye concentration, temperature, and adsorbent dosage). The model equation is expressed in Equation (2):

$\mathrm{R}(\%)=X_{0}+X_{1} \mathrm{~A}+X_{2} \mathrm{~B}+X_{3} \mathrm{C}+X_{4} \mathrm{AB}+X_{5} \mathrm{AC}+X_{6} \mathrm{BC}+X_{7} \mathrm{ABC}$

$\mathrm{R}$ is the response, $\mathrm{X}_{0}$ is the global mean, $\mathrm{X}_{\mathrm{i}}$ is the other regression coefficients and $\mathrm{A}$, $\mathrm{B}, \mathrm{C}$ is the initial dye concentration, temperature, and adsorbent dosage, respectively. $2^{3}$ factorial design cube plot diagrams with high and low three factors are shown to give a better understanding of optimum dye removal conditions. Analysis of variance (ANOVA) was performed to analyze the reliability of the model with a 95\% significance level ( $p$-values $<0.05$ ). All data analysis was analyzed by using Minitab version 16.0 software.

\section{Results and Discussion}

\subsection{Characterization of adsorbents.}

\subsubsection{Scanning Electron Microscope (SEM).}

The morphological features and surface characteristics of peanut husk untreated and after treated with $\mathrm{NaOH}$ were examined using SEM, as shown in Figure 1. These images were used to test for potential changes in morphological characteristics before and after being modified by $\mathrm{NaOH}$. Figure 1 (a) shows that the surface of the given untreated peanut husk presented is irregular, smooth, and compact. Even though there are existed pores and cavities, the number of pores is limited and can be considered as less porous.

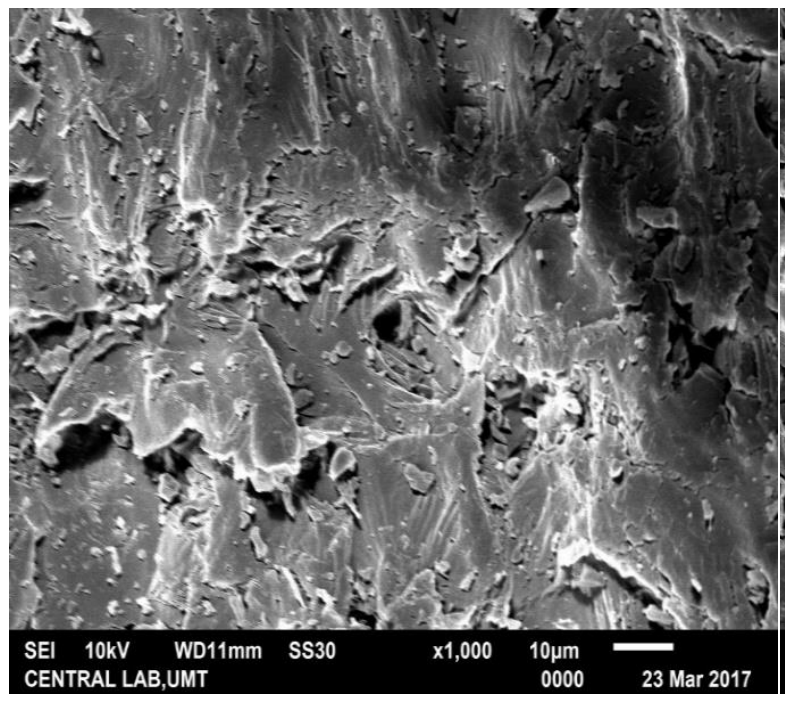

(a)

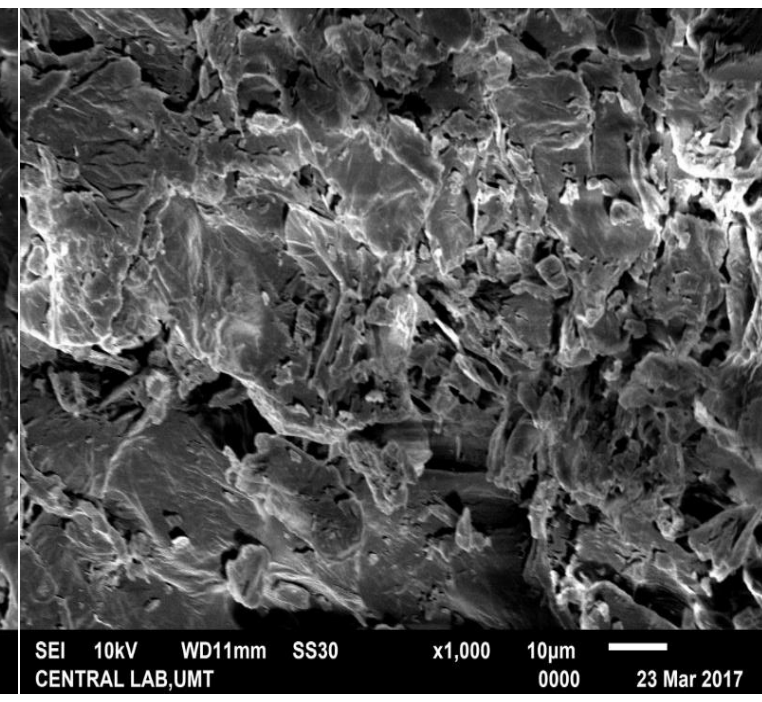

(b)

Figure 1. SEM micrographs of a) untreated, and b) treated peanut husk. 
The treatment of peanut husk with $\mathrm{NaOH}$ has shown improvement in physical characteristics, as shown in Figure 1 (b). The surface of treated peanut husk is rougher compared to untreated conditions. The pores and cavities can be easily observed, and the pores are the deep and more open structure, which indicated that the treated peanut husk has more porous structure. Such characteristics are important for the adsorption process since it makes active sites more accessible and allows larger dye molecules to be diffused [19]. Alkali treatment induced the cracking of pores, and surface roughness increment. It also results in open compact structures indicating the partial removal of the outer non-cellulose layer consisting of materials like hemicellulose, pectin, lignin, wax, and other impurities contained in the adsorbent. Among these materials, wax and pectin are known as a protective layer that surrounds the surface of natural fibers [20].

\subsubsection{Fourier Transform Infrared Spectroscopy (FTIR).}

FTIR spectra analysis was used mainly to identify the existence of available functional groups (carbonyl, hydroxyl, and carboxyl) that were capable of dye adsorption [21]. Figure 2 shown the comparison of FTIR spectra between untreated and treated peanut husk. From this figure, it is evident that some of the peaks have shifted after the peanut husk underwent $\mathrm{NaOH}$ modification. For example, the $\mathrm{O}-\mathrm{H}$ stretching shifted little from $3402.43 \mathrm{~cm}^{-1}$ to $3419.79 \mathrm{~cm}^{-1}$ and C-O stretching from $1041.56 \mathrm{~cm}^{-1}$ to $1045.42 \mathrm{~cm}^{-1}$. Modification of $\mathrm{NaOH}$ can cause swelling that leads to a breakdown of structural connections between lignin and carbohydrates, disruption of the lignin structure, increased internal surface area, decrease in polymerization, and crystallinity [22]. It is believed that MG dye molecules had possessed ionexchange mechanisms which increase the adsorption capacity after alkali treatment. From the FTIR spectra analysis, there existed a large number of hydroxyl and carboxyl groups on the surface of peanut husk. This indicated that these functional groups had the potential to act as active sites for interaction with dye molecules [23].

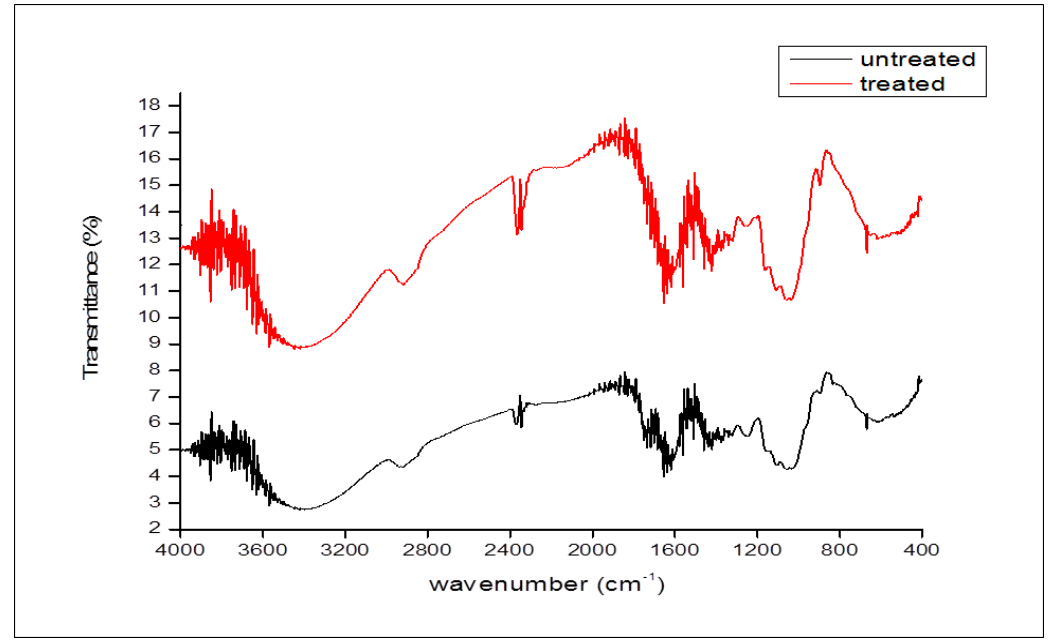

Figure 2. FTIR spectra between untreated and treated peanut husk.

\subsection{Analysis of Surface Area and Pore Size (ASAP).}

The texture properties, such as surface area play an important role in the sorption process of dye molecules [24]. Surface area and pore distribution of untreated and treated peanut husk were measured using BET (Brunauer-Emmett-Teller) and BJH (Barrett-Joyner-Halenda) as shown in Table 2. 
Table 2. BET and BJH analysis results for untreated and treated pea husk

\begin{tabular}{c|c|c} 
Sample & $\begin{array}{c}\text { BET surface area } \\
\left(\mathbf{m}^{2} / \mathbf{g}\right)\end{array}$ & $\begin{array}{c}\text { BJH adsorption average pore } \\
\text { diameter }(\mathbf{n m})\end{array}$ \\
\hline Untreated peanut husk & 1.0191 & 18.5149 \\
\hline Treated peanut husk & 0.6431 & 37.8083
\end{tabular}

From Table 2, BET surface area has shown decrement from $1.0191 \mathrm{~m}^{2} / \mathrm{g}$ to $0.6431 \mathrm{~m}^{2} / \mathrm{g}$ while the $\mathrm{BJH}$ average pore diameter shown increment from $18.5149 \mathrm{~nm}$ to $37.8083 \mathrm{~nm}$. The reduction of surface area can be due to the modification of peanut husk using $\mathrm{NaOH}$, which resulted in the surface of modified samples has been covered by the $\mathrm{NaOH}$ layer. This causes, in part, the observed reduction in the specific surface area by increased mass and partial porosity filling [25]. According to IUPAC classification [26], pore size lies between 2-50nm falls under the mesoporous category. For both samples, they are having mesoporous structure but treated peanut husk has been observed to have a bigger pore size. The tendency of $\mathrm{NaOH}$ activation to produce mesoporous adsorbent was also observed by Ding et al. [27]. The presence of a large number of mesoporous features facilitates the uptake of a larger amount of dye molecules from the liquid phase [24].

\subsection{Results of factorial experimental design by $2^{k}$ full factorial design.}

The results of the adsorption experiment by untreated and treated peanut husk have been tabulated in Table 3. The main effects plot, typical plot, interaction plot, and cube plot have been analyzed and shown in Figure 3. Analysis of Variance (ANOVA) has been tabulated in Table 4. After discarding any insignificant terms, the empirical modeling equation can be represented as in Equation (3) and (4):

$$
\begin{aligned}
& \mathrm{R} 1(\%)=72.363-2.171 \mathrm{~A}+3.152 \mathrm{~B}+6.286 \mathrm{C}-1.926 \mathrm{AB}+2.693 \mathrm{AC}+0.677 \mathrm{BC}-0.965 \mathrm{ABC} \\
& \mathrm{R} 2(\%)=77.549-1.978 \mathrm{~A}+3.892 \mathrm{~B}+7.253 \mathrm{C}-2.225 \mathrm{AB}+3.14 \mathrm{AC}+1.117 \mathrm{BC}-0.955 \mathrm{ABC}
\end{aligned}
$$

Where $\mathrm{R} 1$ and $\mathrm{R} 2$ are the removal rate of untreated and treated peanut husk, respectively, $\mathrm{A}$ is initial dye concentration, $\mathrm{B}$ is temperature, and $\mathrm{C}$ is adsorbent dosage. At the same time, $\mathrm{AB}, \mathrm{AC}, \mathrm{BC}$, and $\mathrm{ABC}$ are the cross product of factors.

\begin{tabular}{|c|c|c|c|c|c|}
\hline \multirow{2}{*}{ Run } & \multicolumn{3}{|c|}{ Variables } & \multirow{2}{*}{$\begin{array}{c}\text { Dye removal of } \\
\text { untreated peanut } \\
\text { husk }\left(\mathbf{R}_{1}\right) \\
(\%)\end{array}$} & \multirow{2}{*}{$\begin{array}{c}\text { Dye removal of } \\
\text { treated peanut } \\
\text { husk }\left(\mathbf{R}_{2}\right) \\
(\%)\end{array}$} \\
\hline & $\mathbf{A}$ & B & $\mathbf{C}$ & & \\
\hline 1 & 100 & 30 & 25 & 59.46 & 63.56 \\
\hline 2 & 100 & 30 & 25 & 59.62 & 63.40 \\
\hline 3 & 100 & 30 & 100 & 78.80 & 84.10 \\
\hline 4 & 25 & 60 & 100 & 84.92 & 91.46 \\
\hline 5 & 100 & 30 & 25 & 60.01 & 64.06 \\
\hline 6 & 100 & 60 & 25 & 63.63 & 66.40 \\
\hline 7 & 25 & 30 & 25 & 68.03 & 70.95 \\
\hline 8 & 25 & 60 & 25 & 74.54 & 79.03 \\
\hline 9 & 100 & 60 & 25 & 62.41 & 67.35 \\
\hline 10 & 25 & 60 & 25 & 73.97 & 80.11 \\
\hline 11 & 25 & 30 & 25 & 67.81 & 71.65 \\
\hline 12 & 25 & 60 & 25 & 74.62 & 79.24 \\
\hline 13 & 25 & 30 & 100 & 71.46 & 75.38 \\
\hline 14 & 100 & 30 & 100 & 78.03 & 84.21 \\
\hline
\end{tabular}

Table 3. Results of adsorption experiment by untreated and treated peanut husk. 


\begin{tabular}{|c|c|c|c|c|c|}
\hline \multirow{2}{*}{ Run } & \multicolumn{3}{|c|}{ Variables } & \multirow{2}{*}{$\begin{array}{c}\text { Dye removal of } \\
\text { untreated peanut } \\
\text { husk }\left(\mathbf{R}_{1}\right) \\
(\%)\end{array}$} & \multirow{2}{*}{$\begin{array}{c}\text { Dye removal of } \\
\text { treated peanut } \\
\text { husk }\left(\mathbf{R}_{2}\right) \\
(\%)\end{array}$} \\
\hline & $\mathbf{A}$ & B & $\mathbf{C}$ & & \\
\hline 15 & 25 & 60 & 100 & 84.49 & 91.43 \\
\hline 16 & 100 & 60 & 100 & 80.46 & 88.13 \\
\hline 17 & 25 & 60 & 100 & 85.14 & 92.59 \\
\hline 18 & 100 & 30 & 100 & 77.87 & 84.10 \\
\hline 19 & 25 & 30 & 100 & 71.51 & 75.59 \\
\hline 20 & 100 & 60 & 100 & 79.85 & 87.18 \\
\hline 21 & 25 & 30 & 100 & 71.24 & 75.38 \\
\hline 22 & 25 & 30 & 25 & 66.68 & 71.51 \\
\hline 23 & 100 & 60 & 25 & 62.14 & 66.29 \\
\hline 24 & 100 & 60 & 100 & 80.02 & 88.07 \\
\hline
\end{tabular}

Table 4. Analysis of Variance (ANOVA) for removal rate, R (\%) of untreated and treated peanut husk.

\begin{tabular}{|c|c|c|c|c|c|c|c|}
\hline Source & Seq. SS & Adj. SS & Adj. MS & $\mathbf{F}$ & $\mathbf{P}$ & $\mathbf{R}^{2}$ & $\begin{array}{c}\mathbf{R}^{\mathbf{2}} \\
\text { (pred.) }\end{array}$ \\
\hline \multicolumn{8}{|c|}{ Untreated peanut husk $\left(\mathbf{R}_{1}\right)$} \\
\hline A & 113.112 & 113.112 & 113.119 & 490.61 & 0.000 & 0.9970 & 0.9948 \\
\hline $\mathrm{B}$ & 238.50 & 238.50 & 238.502 & 1034.42 & 0.000 & & \\
\hline $\mathrm{C}$ & 948.24 & 948.24 & 948.238 & 4112.66 & 0.000 & & \\
\hline $\mathrm{AB}$ & 89.07 & 89.07 & 89.068 & 386.30 & 0.000 & & \\
\hline $\mathrm{AC}$ & 174.10 & 174.10 & 174.099 & 755.10 & 0.000 & & \\
\hline $\mathrm{BC}$ & 10.99 & 10.99 & 10.993 & 47.68 & 0.000 & & \\
\hline $\mathrm{ABC}$ & 22.35 & 22.35 & 22.354 & 96.95 & & & \\
\hline \multicolumn{8}{|c|}{ Treated peanut husk $\left(\mathbf{R}_{2}\right)$} \\
\hline A & 93.88 & 93.88 & 93.88 & 451.59 & 0.000 & 0.9984 & 0.9965 \\
\hline $\mathrm{B}$ & 363.54 & 363.54 & 363.54 & 1748.72 & 0.000 & & \\
\hline $\mathrm{C}$ & 1262.44 & 1262.44 & 1262.44 & 6072.68 & 0.000 & & \\
\hline $\mathrm{AB}$ & 118.81 & 118.81 & 118.81 & 571.50 & 0.000 & & \\
\hline $\mathrm{AC}$ & 236.67 & 236.67 & 236.67 & 1138.47 & 0.000 & & \\
\hline $\mathrm{BC}$ & 29.95 & 29.95 & 29.95 & 144.06 & 0.000 & & \\
\hline$\overline{\mathrm{ABC}}$ & 21.88 & 21.88 & 21.88 & 105.25 & & & \\
\hline
\end{tabular}

The interaction factors influencing the removal of MG dye were calculated by conducting the analysis of variance (ANOVA), as shown in Table 4. All the factors were potentially significant, with a 95\% confidence level and the $\mathrm{P}$-value of less than $0.05(\mathrm{P}<0.05)$. Also, the model presented a real square correlation coefficient R-square of $99.7 \%$, indicating that the data are fitting the statistical model well.

Figure 3 shows that all three factors: $\mathrm{A}$ is dye concentration, $\mathrm{B}$ is temperature, and $\mathrm{C}$ is the adsorbent dosage, and interaction of $\mathrm{AB}, \mathrm{AC}, \mathrm{BC}$ and $\mathrm{ABC}$ have a statistically significant effect on removal of $\mathrm{MG}$ dye for both untreated and treated peanut husk. In detail, $\mathrm{A}, \mathrm{AB}$, and $\mathrm{ABC}$ lie on the left side of the line and has a negative effect, while $\mathrm{B}, \mathrm{C}, \mathrm{AC}$, and $\mathrm{BC}$ fall on the right side has a positive effect. Adsorbent dosage (C) had the largest effect on the process of adsorption, followed by $\mathrm{B}, \mathrm{AC}, \mathrm{A}, \mathrm{AB}, \mathrm{ABC}$, and $\mathrm{BC}$.

Figure 4 has revealed that the adsorption shown the highest removal rate with the darkest color. For example, the graph of temperature against dye concentration has shown that with increasing temperature and decreasing dye concentration, the removal rate has given the highest value of more than $80 \%$, and the color represented was the darkest green. This concept was applicable to the other graphs. For the optimization process, the results have shown that $25 \mathrm{mg} / \mathrm{L}$ of dye concentration, $60^{\circ} \mathrm{C}$ of temperature, and $100 \mathrm{mg}$ of adsorbent dosage gave the highest removal efficiency of $84.85 \%$ and $91.83 \%$ for untreated and treated adsorbent, respectively. 


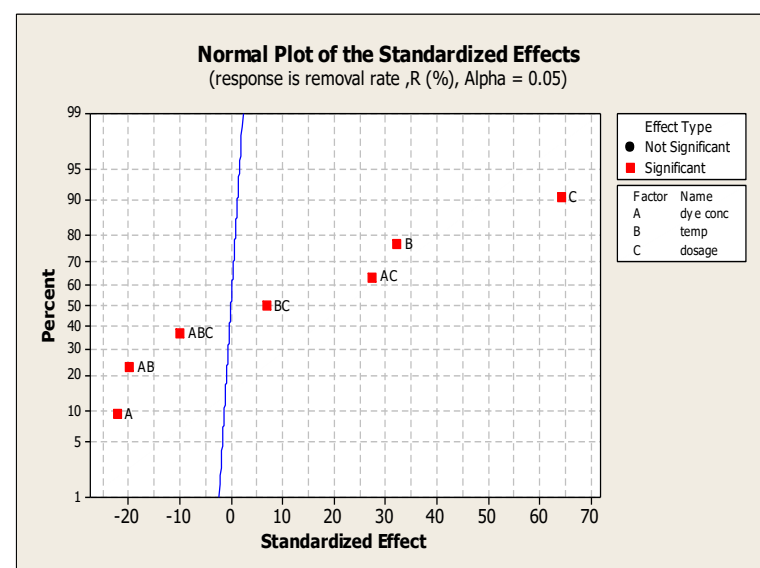

(a)

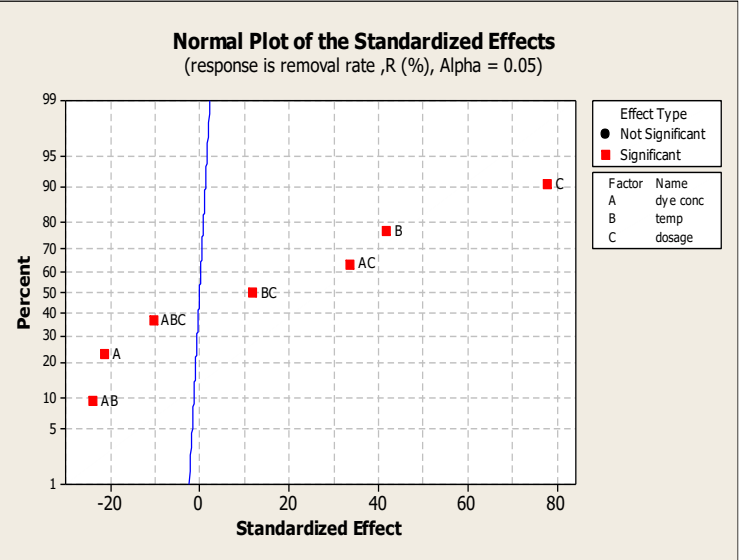

(b)

Figure 3. Normal Plot of the Standardized Effects of a) untreated; and b) treated peanut husk.

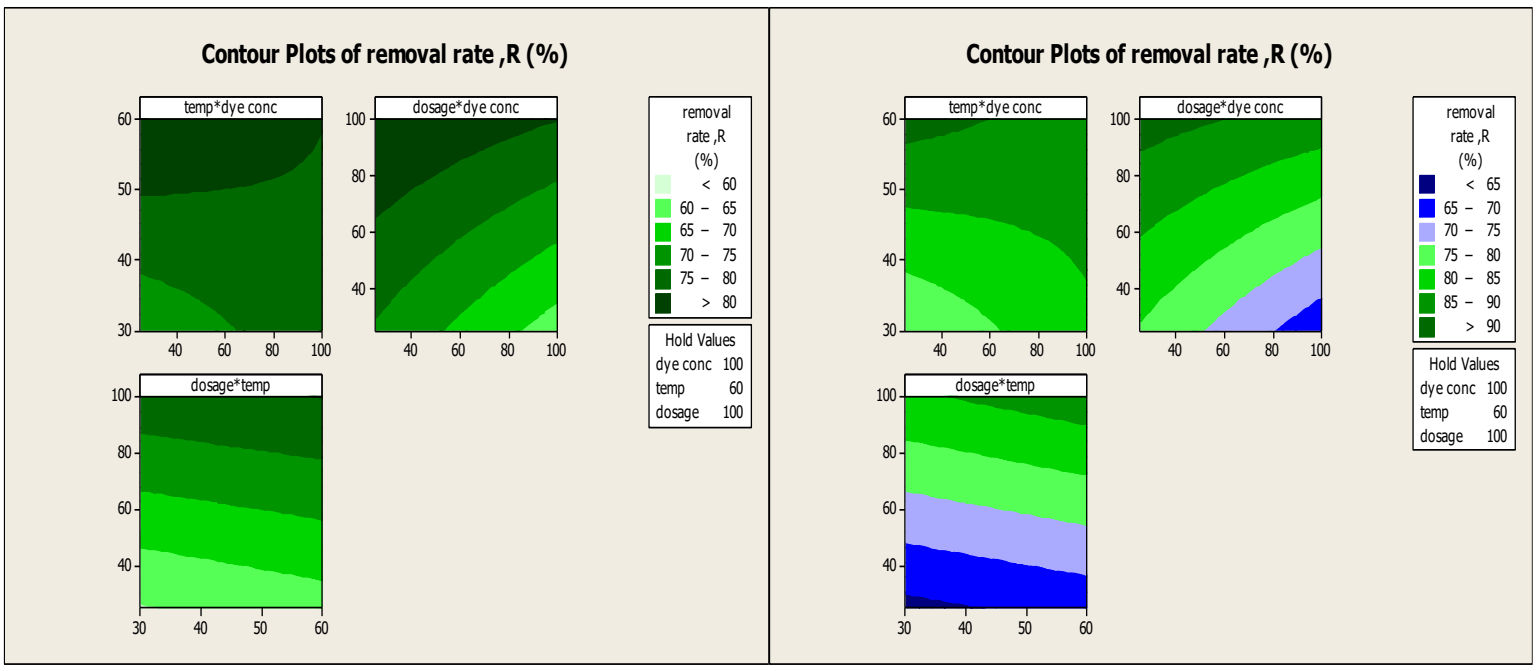

(a)

(b)

Figure 4. Contour Plot of removal rate, R (\%) for a) untreated; and b) treated peanut husk.

\section{Conclusions}

In the present work, a $2^{3}$ full factorial design of experiments are employed to study the removal of MG dye for both untreated and treated peanut husk as an absorbent. SEM, FTIR, BET and BJH analysis were studied to confirm the compatibility of untreated and treated peanut husk. For the optimization process, the results have shown that $25 \mathrm{mg} / \mathrm{L}$ of dye concentration, $60{ }^{\circ} \mathrm{C}$ of temperature, and 100mg of adsorbent dosage gave the highest removal efficiency of $84.85 \%$ and $91.83 \%$ for untreated and treated adsorbent, respectively. In conclusion, treated peanut husk has shown its great potential as low-cost adsorbent based on characterization and the removal efficiency.

\section{Funding}

This research received no external funding.

\section{Acknowledgments}

The authors are thankful to the Universiti Malaysia Terengganu for providing facilities for this research. 


\section{Conflicts of Interest}

\section{The authors declare no conflict of interest.}

\section{References}

1. Anuar, F.I.; Hadibarata, T.; Syafrudin, M.; Fona, Z. Removal of Procion Red MX- 5B from aqueous solution by adsorption on Parkia speciosa (stink bean) peel powder. Biointerface Res. Appl. Chem. 2020, 10, 47744779, https://doi.org/10.33263/BRIAC101.774779.

2. Reddy, P.M.K.; Verma, P.; Subrahmanyam, C. Bio-waste derived adsorbent material for methylene blue adsorption. J. Taiwan Inst. Chem. Engin. 2016, 58 500-508. https://doi.org/10.1016/j.jtice.2015.07.006.

3. Katheresan, V.; Kansedo, J.; Lau, S.Y. Efficiency of various recent wastewater dye removal methods: A review. J. Environ. Chem. Eng. 2018, 6, 4676-4697, https://doi.org/10.1016/j.jece.2018.06.060.

4. Geyikçi, F.; Büyükgüngör, H. Factorial experimental design for adsorption silver ions from water onto montmorillonite. Acta Geodynamica et Geomaterialia, 2013, 10, 363-370. https://doi.org/10.13168/AGG.2013.0035.

5. Saleem, J.; Shahid, U.; Hijab, M.; Mackey, H; Mckay, G. Production and applications of activated carbons as adsorbents from olive stones. Biomass Conv. Bioref. 2019, 9, 775-802, https://doi.org/10.1007/s13399-01900473-7.

6. Banerjee, S.; Sharma, G.C.; Gautam, R.K.; Chattopadhyaya, M.C.; Upadhyay, S.N.; Sharma, Y.C. Removal of Malachite Green, a hazardous dye from aqueous solutions using Avena sativa (oat) hull as a potential adsorbent. J. Mol. Liq. 2016, 213, 162-172. https://doi.org/10.1016/j.molliq.2015.11.011.

7. Kristanti, R.A.; Hadibarata, T.; Al Qahtani, H.M.S. Adsorption of bisphenol A on oil palm biomass activated carbon: characterization, isotherm, kinetic and thermodynamic studies. Biointerface Res. Appl. Chem. 2019, 9, 4217-4224, https://doi.org/10.33263/BRIAC95.217224.

8. Aziz, E.K.; Abdelmajid, R.; Rachid, L.M.; Mohammadine, E.H. Adsorptive removal of anionic dye from aqueous solutions using powdered and calcined vegetables wastes as low-cost adsorbent. Arab J. Basic Appl. Sci. 2018, 25, 93-102, https://doi.org/10.1080/25765299.2018.1517861

9. Kanthasamy, S.; Hadibarata, T.; Hidayat, T.; Alamri, S.A.; Ahmed al-Ghamdi, A. Adsorption of azo and anthraquinone dye by using watermelon peel powder and corn peel powder: Equilibrium and kinetic studies. Biointerface Res. Appl. Chem. 2020, 10, 4706-4713, https://doi.org/10.33263/BRIAC101.706713.

10. Kuang, Y.; Zhang, X.; Zhou, S. Adsorption of methylene blue in water onto activated carbon by surfactant modification. Water 2020, 12, 87-93, https://doi.org/10.3390/w12020587.

11. Hamzah, S.; Razali, N.A.; Yatim, N.I.; Alias, M.; Ali, A.; Zaini, N.S.; Azzam, A.M.A. Characterisation and performance of thermally treated rice husk as efficient adsorbent for phosphate removal. J. Water Suppl. Res. Technol.-Aqua 2018, 67, 766-778, https://doi.org/10.2166/aqua.2018.087.

12. Bowden, G.D.; Pichler B. J.; Maurer, A. A design of experiments (DOE) approach accelerates the optimization of copper-mediated 18f-fluorination reactions of arylstannanes. Scientific reports 2019, 9, 11370-11380, https://doi.org/10.1038/s41598-019-47846-6.

13. Mohammad, Y.S.; Shaibu-Imodagbe, E.M.; Igboro, S.B.; Giwa, A.; Okuofu, C.A. Adsorption of phenol from refinery wastewater using rice husk activated carbon. Iran. J. Energy Environ. 2014, 5, 393-399. https://doi.org/10.5829/idosi.ijee.2014.05.04.07.

14. Sharma, S.; Saxena, R.; Gaur, G. Study of removal techniques for azo dyes by biosorption: a review. J. Appl. Chem. 2014, 7, 6-21, https://doi.org/10.9790/5736-071010621.

15. Prapagdee, S.; Piyatiratitivorakul, S.; Petsom, A. Physico-chemical activation on rice husk biochar for enhancing of cadmium removal from aqueous solution. Asian J. Wat. Environ. Poll. 2016, 13, 27-34, https://doi.org/10.3233/AJW-160004.

16. Wayland, H.A.; Boury, S.N.; Chhetri, B.P.; Brandt, A.; Proskurnin, M.A.; Filichkina, V.A.; Ghosh, A. Advanced cellulosic materials for treatment and detection of industrial contaminants in wastewater. ChemistrySelect 2016, 1, 4472-4488, https://doi.org/10.1002/slct.201600653.

17. Hemmati, F.; Norouzbeigi, R.; Sarbisheh, F.; Shayesteh, H. Malachite green removal using modified sphagnum peat moss as a low-cost biosorbent: Kinetic, equilibrium and thermodynamic studies. J. Taiwan Inst. Chem. Eng. 2015, 58, 482-489, https://doi.org/10.1016/j.jtice.2015.07.004. 
18. Leng, L.; Yuan, X.; Zeng, G.; Shao, J.; Chen, X.; Wu, Z.; Wong, H.; Peng, X. Surface characterization of rice husk bio-char produced by liquefaction and application for cationic dye (Malachite green) adsorption. Fuel 2015, 155, 77-85, http://dx.doi.org/10.1016\%2Fj.fuel.2015.04.019.

19. Boadu, K.O.; Joel, O.F.; Essumang, D.K.; Evbuomwan B.O. Comparative studies of the physicochemical properties and heavy metals adsorption capacity of chemical activated carbon from palm kernel, coconut and groundnut shells. J. Appl. Sci. Environ. Manage 2018, 22, 1833-1839, https://doi.org/10.4314/jasem.v22i11.19.

20. Vitas, S.; Segmehl, J.S.; Burgert, I.; Cabane, E. Porosity and pore size distribution of native and delignified beech wood determined by mercury intrusion porosimetry. Materials 2019, 12, 1-13, https://doi.org/10.3390/ma12030416.

21. Oyekanmi, A.A.; Ahmad, A.; Hossain, K.; Rafatullah, M. Adsorption of Rhodamine B dye from aqueous solution onto acid treated banana peel: Response surface methodology, kinetics and isotherm studies. PLoS ONE 2019, 14, 1-20, https://doi.org/10.1371/journal.pone.0216878.

22. Kucharska, K.; Rybarczyk, P.; Hołowacz, I.; Łukajtis, R.; Glinka, M.; Kamiński, M. Pretreatment of lignocellulosic materials as substrates for fermentation processes. Molecules 2018, 23, 1-32, https://doi.org/10.3390/molecules23112937.

23. Karimi Darvanjooghi, M. H.; Davoodi, S.M.; Dursun, A.Y.; Ehsani, M.R.; Karimpour, I.; Ameri, E. Application of treated eggplant peel as a low-cost adsorbent for water treatment toward elimination of $\mathrm{Pb}^{2+}$ : Kinetic modeling and isotherm study. Adsorp. Sci. Technol. 2018, 36, 11121143, https://doi.org/10.1177/0263617417753784.

24. Banerjee, S.; Sharma, G.C.; Gautam, R.K.; Chattopadhyaya, M.C.; Upadhyay, S.N.; Sharma, Y.C. Removal of Malachite Green, a hazardous dye from aqueous solutions using Avena sativa (oat) hull as a potential adsorbent. J. Molecular Liquids 2016, 213,162-172, http://dx.doi.org/10.1016\%2Fj.molliq.2015.11.011.

25. Salonen, J.; Gubal, A.; Ganeev, A.A.; Tang, W.Z.; Ermei, M.; Kamwilaisak, K.; Wang, S. Modified and unmodified low-cost iron-containing solid wastes as adsorbents for efficient removal of As (III) and As (V) from mine water. J. Clean. Prod. 2016, 133, 1095-1104, https://doi.org/10.1016/j.jclepro.2016.05.147.

26. Morsi, R.E.; Mohamed, R.S. Nanostructured mesoporous silica: influence of the preparation conditions on the physical-surface properties for efficient organic dye uptake. Royal Soc. Open Sci. 2018, 5, 1-15, https://doi.org/10.1098/rsos.172021.

27. Ding, L.; Zou, B.; Li, Y.; Liu, H.; Wang, Z.; Zhao, C. Su, Y.; Guo, Y. The production of hydrochar-based hiererchical porous carbons for use as electrochemical supercapacitor electrode materials. Colloids Surf. A: Physicochem. Eng. Asp. 2013, 423, 104-111, https://doi.org/10.1016/j.colsurfa.2013.02.003. 